\title{
Hubungan Performa Fisik dengan Prognosis Pasien Gagal Jantung
}

\author{
Nurfadhilah H. Palilati, ${ }^{1}$ Frans E. N. Wantania, ${ }^{2}$ Linda W. A. Rotty ${ }^{2}$
}

\author{
${ }^{1}$ Program Studi Pendidikan Dokter Fakultas Kedokteran Universitas Sam Ratulangi, Manado, \\ Sulawesi Utara, Indonesia \\ ${ }^{2}$ Bagian Ilmu Penyakit Dalam Fakultas Kedokteran Universitas Sam Ratulangi, Manado, \\ Sulawesi Utara, Indonesia \\ Email: dilapalilati@gmail.com
}

\begin{abstract}
Heart failure is a serious health problem and a leading cause of death, illness, and poor quality of life. Although the diagnosis and treatment of this disease has significant progress, the prognosis is still poor. The physical performance of patients with heart failure, for example, measured by a 6-minute walking test can be used to assess the functional capacity and assess the prognosis of the patient. This study was aimed to determine the relationship between physical performance and prognosis of patients with heart failure. This was a literature review study using literatures obtained from three databases, namely Pubmed, Science Direct, and Google Scholar. The keywords used in searching the literatures were "physical performance OR 6 minutes walking test AND heart failure prognosis" and their variations and translations. After the selection, 10 literatures were reviewed. The results showed that any decreases in distance of the 6-minute walking test and in walking speed would increase the risk of rehospitalization and mortality as reported in nine literatures. In conclusion, there was a significant relationship between physical performance and prognosis of patients with heart failure.
\end{abstract}

Keywords: physical performance, prognosis of heart failure

\begin{abstract}
Abstrak: Gagal jantung merupakan masalah kesehatan yang serius dan penyebab utama kematian, kesakitan, serta kualitas hidup yang buruk. Meskipun diagnosis dan pengobatan penyakit ini telah mengalami banyak kemajuan namun prognosisnya masih buruk. Performa fisik pasien gagal jantung contohnya diukur dengan tes jalan 6 menit dapat digunakan untuk menilai kapasitas fungsional dan menilai prognosis dari pasien. Penelitian ini bertujuan untuk mengetahui hubungan performa fisik dengan prognosis pasien gagal jantung. Jenis penelitian ialah literature review menggunakan literatur yang diperoleh dari tiga database yaitu Pubmed, Science Direct. dan Google Scholar. Kata kunci yang digunakan dalam pencarian artikel yaitu "physical performance OR 6 minutes walking test AND heart failure prognosis" dan berbagai variasi serta terjemahan. Hasil seleksi, mendapatkan 10 literature yang dikaji. Hasil penelitian mendapatkan bahwa setiap penurunan jarak yang ditempuh dalam uji jalan 6 menit dan penurunan waktu kecepatan berjalan dapat meningkatkan risiko rehospitalisasi dan kematian yang dilaporkan pada 9 literatur. Simpulan penelitian ini ialah terdapat hubungan bermakna antara performa fisik dengan prognosis pada pasien gagal jantung.
\end{abstract}

Kata kunci: performa fisik, prognosis gagal jantung

\section{PENDAHULUAN}

Gagal jantung adalah keadaan dimana jantung tidak mampu memompa darah secara cukup ke seluruh tubuh untuk dapat memenuhi kebutuhan tubuh. ${ }^{1}$ Gagal jantung memiliki tampilan gejala yang khas, yaitu sesak saat istirahat atau pada saat aktivitas, sering kelelahan, serta adanya tanda retensi cairan seperti kongesti paru ataupun edema pada pergelangan kaki. Di Indonesia, berdasarkan data dari Departemen Kesehatan tahun 2008, pasien gagal jantung yang dirawat mencapai $14.449 .^{2}$ Berdasarkan data menurut diagnosis dokter, pada tahun 2013 
prevalensi penyakit gagal jantung di Indonesia sebesar $0,13 \%$ atau diperkirakan sekitar 229.696 orang. $^{3}$

Pada gagal jantung, walaupun mekanisme kompensasi memiliki kemungkinan mampu untuk mempertahankan curah jantung saat istirahat, namun hal ini mungkin tidak cukup saat pasien menjalani latihan fisik. Fungsi jantung akan menurun, dan gagal jantung menjadi berat. ${ }^{4}$

Perubahan hemodinamik berupa penurunan curah jantung, volume sekuncup, dan juga fraksi ejeksi dapat menyebabkan terjadinya gejala berupa sesak napas, kelelahan, dan intoleransi latihan fisik. Intoleransi latihan fisik atau berkurangnya toleransi latihan merupakan faktor utama dari terjadinya penurunan fungsi sosial, fisik, serta kualitas hidup dan dapat meningkatkan kemungkinkan untuk terjadinya kejadian kardiovaskular. ${ }^{5}$

Sebagian besar sumber daya perawatan kesehatan digunakan untuk mengobati pasien gagal jantung, dengan biaya lebih banyak dikeluarkan untuk rawat inap. Meskipun diagnosis dan pengobatan penyakit ini sudah mengalami banyak kemajuan namun prognosisnya masih buruk. ${ }^{6,7}$

Sejalan dengan hasil penelitian Dunlay tahun 2012 yang menyatakan bahwa pada pasien gagal jantung secara umum sulit untuk melakukan kegiatan aktivitas seharihari, yang berkembang dari waktu ke waktu pada banyak individu dan merupakan penanda kuat dari prognosis buruk. ${ }^{8}$

Ingle et $\mathrm{al}^{9}$ melaporkan bahwa intensitas latihan pada tes jalan 6 menit untuk mengukur performa fisik pasien dapat meniru dan sesuai dengan aktivitas atau kegiatan keseharian pasien gagal jantung ringan sampai sedang. Penurunan jarak pada tes jalan 6 menit merupakan prediktor independen dari peningkatan mortalitas pada pasien dengan disfungsi ventrikel kiri. Sebagian besar penelitian sebelumnya telah menunjukkan bahwa jarak yang ditempuh oleh pasien yang dirawat di rumah sakit selama tes berjalan 6 menit merupakan prediksi risiko satu tahun kematian akibat kardiovaskular. ${ }^{9,10}$

\section{METODE PENELITIAN}

Penelitian ini berbentuk literature review. Berdasarkan hasil penelusuran dari tiga database yaitu Pubmed, Science Direct dan Google Scholar dengan kata kunci (physical performance OR 6 minutes walking test AND heart failure prognosis) dan berbagai variasi serta terjemahannya, penulis menyeleksi artikel dengan kriteria inklusi dan eksklusi sehingga didapatkan 10 jurnal full text yang dilakukan kajian.

\section{HASIL PENELITIAN}

Setelah melalui tahap seleksi studi, didapatkan 10 jurnal penelitian yang sesuai kriteria penelitian. Dari 10 jurnal, terdapat sembilan jurnal dari luar negeri dan satu jurnal dari Indonesia. Jumlah sampel penelitian tiap literatur bervariasi, dengan total berjumlah sampai ribuan pasien gagal jantung dengan kelas NYHA yang berbedabeda. Dari 10 jurnal, tujuh jurnal menggunakan tes jalan 6 menit untuk mengukur performa fisik, dan tiga jurnal menggunakan tes kecepatan berjalan. Tabel 1 memperlihatkan hasil kajian 10 literatur yang dipakai dalam penelitian ini.

Tabel 1. Analisis jurnal berdasarkan peneliti, jumlah sampel, pengukuran performa fisik, dan ringkasan hasil

\begin{tabular}{ccll}
\hline Peneliti & $\begin{array}{c}\text { Jumlah } \\
\text { Sampel }\end{array}$ & $\begin{array}{c}\text { Pengukuran } \\
\text { Performa Fisik }\end{array}$ & Ringkasan Hasil \\
\hline Cahalin et al $^{11}$ & 258 & $\begin{array}{l}\text { Tes jalan 6 } \\
\text { menit }\end{array}$ & $\begin{array}{l}\text { Selama follow-up 22 bulan, terdapat 48 kematian dan 2 } \\
\text { transplantasi jantung mendesak pada 50 pasien dengan jarak }\end{array}$ \\
& & 6 MWT dan HRR yang rendah. Hasil analisis regresi HRR \\
& & setelah 6 MWT yang digunakan untuk mengukur performa \\
& & fisik pasien efektif digunakan sebagai prediktor efek samping \\
& & yang signifikan (p<0,001). Keterangan: Terdapat hubungan \\
& & antara performa fisik dengan prognosis pada pasien gagal \\
\hline
\end{tabular}


Lo et $\mathrm{al}^{12}$

1.119

Pulignano et $\mathrm{al}^{13}$

331

Kecepatan berjalan sejauh 4 $\mathrm{m}$

Kecepatan berjalan 15 kaki

jantung.

Secara keseluruhan,selama 1 tahun penilaian, 740 peserta (66\%) dari 1.119 peserta meninggal. Kecepatan berjalan (HR 1,37, interval kepercayaan 95\% 1,10 hingga 1,70; $p=0,004$ ) dan IADL (HR 1,56, interval kepercayaan 95\% 1,29-1,89; $\mathrm{p}<0,001)$ yang diukur dalam waktu 1 tahun merupakan faktor risiko penting untuk kematian pada orang dewasa $\geq 65$ tahun dengan gagal jantung.

Keterangan: Terdapat hubungan antara performa fisik dengan prognosis pada pasien gagal jantung

Selama 1 tahun follow-up, 80 pasien meninggal dan 125 pasien pernah dirawat inap di rumah sakit karena gagal jantung yang lebih parah. Ada hubungan yang signifikan antara kecepatan berjalan dan kematian 1 tahun $(\mathrm{p}<0,001)$. Hasil penelitian ini menegaskan bahwa pasien dengan gagal jantung memiliki gangguan dalam kecepatan berjalan, dan kecepatan berjalan yang lambat berkaitan dengan hasil klinis atau prognosis yang buruk. Keterangan: Terdapat hubungan antara performa fisik dengan prognosis pada pasien gagal jantung

Vidan et $\mathrm{al}^{14}$

450

Kecepatan berjalan sejauh $4,6 \mathrm{~m}$

Ingle et $\mathrm{al}^{9}$

1.667 Tes jalan 6 menit

Harikatang et $\mathrm{al}^{5}$

Tes jalan 6 menit

Boxer et al ${ }^{15}$

60

Tes jalan 6 menit

Arslan et $\mathrm{al}^{16}$

43
Selama 1 tahun follow-up, 90 kematian terjadi, 11 di kelompok yang tidak lemah dan 79 pada kelompok lemah ( $<<0,001)$. Dijelaskan bahwa kerapuhan berkaitan dengan peningkatan 2,13 kali lipat dalam risiko kematian 1 tahun (95\% CI 1,07-4,23) disesuaikan dengan usia, jenis kelamin, penyakit penyerta kronis, keberadaan penyakit akut lainnya, LVEF, kelas NYHA, dan NT-proBNP. Keterangan: Terdapat hubungan antara performa fisik dengan prognosis pada pasien gagal jantung.

Pada 5 tahun follow-up, ditemukan pasien yang meninggal $(\mathrm{n}=959)$. Jarak 6-MWT lebih rendah pada mereka yang meninggal [163 (153) m dibandingkan 269 (160) $\mathrm{m}$ ( $\mathrm{p}<0,0001)$. Keterangan: Terdapat hubungan antara performa fisik dengan prognosis pada pasien gagal jantung

Selama 2 bulan follow-up, didapatkan 17 sampel berjarak tempuh $<300 \mathrm{~m} ; 23,5 \%$ di antaranya mengalami kejadian kardiovaskular (rehospitalisasi dan unstable angina). Responden dengan jarak tempuh >300 m berjumlah 14 orang; 42,8 \% mengalami kejadian kardiovaskular. Hasil uji ChiSquare menunjukkan tidak terdapat hubungan bermakna antara jarak tempuh tes jalan 6 menit dan kejadian kardiovaskular $(\mathrm{p}=0,252)$. Keterangan: Tidak terdapat hubungan antara performa fisik dengan prognosis pada pasien gagal jantung

Dari 20 pasien yang meninggal selama 4 tahun follow-up, ditemukan $60 \%$ pasien yang meninggal dengan $6 \mathrm{MWT} \leq 300$ $\mathrm{m}$ (daya tahan rendah). Skor Uji jalan 6 menit secara independen memprediksi kematian, dengan hazard ratio 0,82 (interval kepercayaan 95\%, 0,72-0,94). Hasil penelitian juga mengungkapkan bahwa 6MWT dikaitkan dengan mortalitas $(p=0,005)$. Keterangan: Terdapat hubungan antara performa fisik dengan prognosis pada pasien gagal jantung

Selama 18 bulan follow-up, didapatkan hasil angka kematian secara signifikan lebih tinggi pada pasien dengan jarak uji jalan 6 menit $\leq 300 \mathrm{~m}$ dibandingkan pada pasien dengan jarak uji jalan 6 menit >300 m (p<0,001). Risiko kematian ditemukan secara signifikan lebih tinggi pada pasien dengan jarak $\leq 300 \mathrm{~m}(\mathrm{p}=0,005)$. Keterangan: Terdapat hubungan antara performa fisik dengan prognosis pada pasien gagal jantung. 


\begin{tabular}{|c|c|c|c|}
\hline Wegrzynowska et al $^{10}$ & 243 & $\begin{array}{l}\text { Tes jalan } 6 \\
\text { menit }\end{array}$ & $\begin{array}{l}\text { Analisis multivariat menunjukkan bahwa semakin pendek } \\
\text { jarak yang ditempuh dalam tes berjalan } 6 \text { menit, semakin } \\
\text { besar risiko kematian yang dipantau selama } 1 \text { tahun dan } 3 \\
\text { tahun. Analisis multivariat juga menunjukkan bahwa risiko } \\
\text { kematian yang lebih tinggi atau rawat inap karena kejadian } \\
\text { kardiovaskular dapat diprediksi dengan jarak berjalan } 6 \text { menit } \\
\leq 468 \text { m. Keterangan: Terdapat hubungan antara performa } \\
\text { fisik dengan prognosis pada pasien gagal jantung. }\end{array}$ \\
\hline Alahdab et $a l^{17}$ & 200 & $\begin{array}{l}\text { Tes jalan } 6 \\
\text { menit }\end{array}$ & $\begin{array}{l}\text { Selama } 40 \text { bulan follow-up, didapatkan untuk pasien yang } \\
\text { berjalan } \leq 200 \mathrm{~m} \text { selama uji jalan } 6 \text { menit, mortalitas adalah } \\
41 \% \text { dibandingkan dengan pasien yang berjalan }>200 \text { m yaitu } \\
19 \%(p<0.001) \text {. Untuk pasien yang berjalan } \leq 200 \mathrm{~m} \text { selama } \\
\text { uji jalan } 6 \text { menit, kejadian rawat inap kembali karena gagal } \\
\text { jantung adalah } 68 \% \text { dibandingkan dengan mereka yang } \\
\text { berjalan }>200 \mathrm{~m} \text { yaitu } 52 \% \text { ( }=0,027 \text { ). Keterangan: Terdapat } \\
\text { hubungan antara performa fisik dengan prognosis pada } \\
\text { pasien gagal jantung }\end{array}$ \\
\hline
\end{tabular}

\section{BAHASAN}

Performa fisik pada penelitian ini diukur dari pemeriksaan tes berjalan selama 6 menit dan kecepatan berjalan biasa pasien tanpa berlari. Dari 10 laporan tersebut, didapatkan sebanyak lima artikel penelitian yang melaporkan bahwa jarak tes berjalan selama 6 menit (6 minutes walking test 6MWT) dapat digunakan sebagai prediktor terjadinya kematian pada pasien penderita gagal jantung. Jarak berjalan yang lebih rendah didapatkan berhubungan dengan peningkatan risiko kematian dan risiko dirawat inap ulang dalam jangka waktu 1-3 tahun.

Sebanyak dua penelitian melaporkan bahwa jarak dari tes jalan 6 menit yang kurang dari 200 meter merupakan batas terjadinya peningkatan risiko kematian dan rawat inap yang bermakna. Salah satu dari dua penelitian tersebut yaitu penelitian oleh Alahdab et $\mathrm{al}^{17}$ di Amerika Serikat menyebutkan bahwa pasien gagal jantung dengan jarak 6MWT kurang dari 200 meter akan memiliki risiko 2,14 kali lebih tinggi untuk mengalami kematian dan 1,62 kali lebih tinggi untuk dirawat inap ulang dalam rentang waktu 1 tahun.

Sementara itu, tiga penelitian lain melaporkan batas jarak yang berbeda. Dua penelitian yang dilakukan oleh Boxer et al ${ }^{15}$ di Amerika Serikat dan Arslan et al ${ }^{16}$ di Turki melaporkan bahwa pasien gagal jantung yang menempuh jarak kurang dari
300 meter saat menjalani 6MWT, akan memiliki risiko yang lebih besar untuk mengalami kematian dalam jangka waktu 1 tahun. Terdapat aatu penelitian lainnya oleh Wegrzynowska et $\mathrm{al}^{10}$ di Polandia yang melaporkan bahwa jarak tempuh 6MWT kurang dari 468 meter akan berhubungan dengan peningkatan risiko kematian sebesar 3,22 kali lipat dalam waktu 1 tahun dan 2,18 kali lipat dalam waktu 3 tahun. ${ }^{10,15,16}$

Beberapa penelitian juga menginvestigasi komponen lain dari tes berjalan 6 menit. Satu artikel penelitian melaporkan bahwa prediktor prognosis bagi pasien gagal jantung yang terbaik bukanlah jarak 6MWT, melainkan Heart Rate Recovery (HRR). ${ }^{11}$ Komponen lain yang juga cukup banyak diteliti ialah kecepatan berjalan saat menjalani 6MWT. Sebanyak tiga artikel penelitian melaporkan bahwa kecepatan berjalan merupakan prediktor kematian dalam 1 tahun yang akurat pada pasien gagal jantung, terutama pada lansia. Salah satu laporan penelitian menyebutkan bahwa pasien gagal jantung dengan kecepatan berjalan yang lambat akan memiliki risiko 1,77 kali lebih tinggi untuk mengalami kematian, dibandingkan pasien dengan kecepatan berjalan yang normal. ${ }^{12-14}$

Berbeda dengan penelitian lain yang menyimpulkan bahwa terdapat hubungan performa fisik dengan prognosis pasien gagal jantung, satu laporan penelitian yang dilakukan oleh Harikatang at $\mathrm{al}^{5}$ di Indo- 
nesia yang melaporkan bahwa jarak yang ditempuh saat 6MWT tidak berhubungan dengan kejadian kardiovaskular. Terdapat perbedaan ukuran prognosis antara beberapa penelitian yang telah disebutkan sebelumnya dengan penelitian ini. Beberapa penelitian tersebut menggunakan kematian dan kejadian rawat inap ulang sebagai ukuran prognosis, sedangkan penelitian ini menggunakan kejadian kardiovaskular yang diartikan sebagai terjadinya stroke, unstable angina, rehospitalisasi, dan kematian. Harikatang et $\mathrm{al}^{5}$ menyatakan bahwa tidak terdapatnya hubungan bermakna dalam penelitiannya kemungkinan dikarenakan waktu follow up yang singkat yaitu hanya 2 bulan dan jumlah sampel yang kurang. ${ }^{5}$

Dari beberapa jurnal yang dikaji, terdapat beberapa faktor lain yang juga disebutkan dan dapat digunakan sebagai prediktor kematian pada pasien gagal jantung. Faktor-faktor tersebut ialah kualitas hidup, usia, jenis kelamin perempuan, NYHA class tinggi, peningkatan NT pro-BNP, penurunan tekanan darah diastolik, penurunan kadar natrium darah, peningkatan urea darah, dan penurunan fraksi ejeksi.

Dari 10 literatur yang dikaji, sembilan literatur menjelaskan bahwa terdapat hubungan performa fisik dengan prognosis pasien gagal jantung. Hal ini didukung oleh penelitian systematic review yang dilakukan oleh Yamamoto et al $^{18}$ di Jepang tahun 2020 yang menyatakan bahwa terdapat hubungan bermakna antara performa fisik (diukur dengan tes jalan 6 menit/6MWT dan kecepatan berjalan) dengan prognosis pasien gagal jantung.

\section{SIMPULAN}

Performa fisik, khususnya jarak yang ditempuh pada tes jalan 6 menit (6MWT) dan waktu kecepatan berjalan, dapat digunakan sebagai prediktor prognosis pada pasien gagal jantung. Semakin rendah jarak tempuh pada tes jalan 6 menit (6MWT) dan waktu pada kecepatan berjalan, maka semakin tinggi risiko terjadinya kematian pada pasien gagal jantung. Terdapat hubungan bermakna antara performa fisik dengan prognosis pada pasien gagal jantung.

\section{Konflik Kepentingan}

Penulis menyatakan tidak terdapat konflik kepentingan dalam studi ini.

\section{DAFTAR PUSTAKA}

1. Wahyuni A, Sari KO. Hubungan self care dan motivasi dengan kualitas hidup pasien gagal jantung. J Keperawatan Padjadjaran. 2014;2(2):108-15.

2. Imaligy UE. Gagal jantung pada geriatri. CKD212. 2014;4(1):19-24.

3. Kemenkes RI. Situasi kesehatan jantung. Pus data dan Inf Kementeri Kesehat RI [Internet]. 2014;3. Available from: http://www.depkes.go.id/download.php ?file=download/pusdatin/infodatin/info datin-jantung.pdf

4. Tanai E, Frantz S. Pathophysiology of heart failure. Compr Physiol. 2016;6(1):187214.

5. Harikatang $\mathrm{AD}$, Rampengan SH, Jim EL. Hubungan antara jarak tempuh tes jalan 6 menit dan fraksi ejeksi pada pasien gagal jantung kronik terhadap kejadian kardiovaskular. e-CliniC. 2016;4(1).

6. Klompstra L, Jaarsma T, Strömberg A, van der Wal MHL. Seasonal variation in physical activity in patients with heart failure. Heart Lung. 2019;48(5):381-5.

7. Ozturk CT, Unluer E, Denizbasi A, Guneysel O, Onur O. Can NT-proBNP be used as a criterion for heart failure hospitalization in emergency room? J Res Med Sci. 2011;16(12):1564-71.

8. Sekarsari R, Suryani AI. Gambaran aktivitas sehari-hari pada pasien gagal jantung kelas II dan III di Poli Jantung RSU Kabupaten Tangerang. J JKFT. 2017; 1(2): 1

9. Ingle L, Cleland JG, Clark AL. The long-term prognostic significance of 6-minute walk test distance in patients with chronic heart failure. Biomed Res Int. 2014;2014:505969. Doi: 10.1155/2014/ 505969.

10. Wegrzynowska-Teodorczyk K, Rudzinska E, Lazorczyk M, Nowakowska K, Banasiak W, Ponikowski P, et al. Distance covered during a six-minute walk test predicts long-term cardiovascular mortality and hospitalisation rates in men with systolic heart failure: An observational study. J Physiother. 2013; 59(3):177-87.

11. Cahalin LP, Arena R, Labate V, Bandera F, 
Lavie CJ, Guazzi M. Heart rate recovery after the 6 min walk test rather than distance ambulated is a powerful prognostic indicator in heart failure with reduced and preserved ejection fraction: A comparison with cardiopulmonary exercise testing. Eur J Heart Fail. 2013; 15(5):519-27.

12. Lo AX, Donnelly JP, McGwin G, Bittner V, Ahmed A, Brown CJ. Impact of gait speed and instrumental activities of daily living on all-cause mortality in adults $\leq 65$ years with heart failure. Am J Cardiol. 2015;115(6):797-801.

13. Pulignano G, Del Sindaco D, Di Lenarda A, Alunni G, Senni M, Tarantini L, et al. Incremental Value of Gait Speed in Predicting Prognosis of Older Adults With Heart Failure: Insights From the IMAGE-HF Study. JACC Heart Fail. 2016;4(4):289-98.

14. Vidán MT, Blaya-Novakova V, Sánchez E, Ortiz J, Serra-Rexach JA, Bueno H. Prevalence and prognostic impact of frailty and its components in nondependent elderly patients with heart failure. Eur J Heart Fail. 2016;18(7): 869-75.

15. Boxer R, Kleppinger A, Ahmad A, Annis K, Hager D, Kenny A. The 6-minute walk is associated with frailty and predicts mortality in older adults with heart failure. Congest Heart Fail. 2010; 16(5): 208-13.

16. Arslan S, Erol MK, Gundogdu F, Sevimli S, Aksakal E, Senocak H, et al. Prognostic value of 6-minute walk test. Tex Heart IJ. 2007;34(2):166-9.

17. Alahdab MT, Mansour IN, Napan S, Stamos TD. Six minute walk test predicts longterm all-cause mortality and heart failure rehospitalization in African-American patients hospitalized with acute decompensated heart failure. J Card Fail. 2009; 15(2):130-5.

18. Yamamoto S, Yamaga T, Nishie K, Sakai Y, ishida T, Oka K, et al. Impact of physical performance on prognosis among patients with heart failure: systematic review and meta-analysis. J Cardiol. 2020;76(2):139-46. 